Bryn Mawr College

Scholarship, Research, and Creative Work at Bryn Mawr College

Graduate School of Social Work and Social

Graduate School of Social Work and Social

Research Faculty Research and Scholarship

Research

2013

\title{
In Response to Need: An Analysis of Social Work Roles Over Time
}

Toba Schwaber Kerson

Bryn Mawr College, tkerson@brynmawr.edu

Judith McCoyd

Let us know how access to this document benefits you.

Follow this and additional works at: http://repository.brynmawr.edu/gsswsr_pubs

\section{Custom Citation}

Toba Schwaber Kerson and Judith McCoyd, "In Response to Need: An Analysis of Social Work Roles Over Time," Forthcoming in Social Work.

This paper is posted at Scholarship, Research, and Creative Work at Bryn Mawr College. http://repository.brynmawr.edu/gsswsr_pubs/31

For more information, please contact repository@brynmawr.edu. 
In Response to Need: An Analysis of Social Work Roles Over Time

Introduction

Since before 1905 when physician Richard Cabot asked Ida M. Cannon to help him provide more holistic and community-based care for "his" patients, social workers have been on the front line of health care in hospitals, public health settings, mental health organizations, and the community (Gibelman, 1999; http://www.mghpcs.org/socialservice/History.asp ). For social workers "housed" within host settings, the core values of social work and social work roles are often subsumed within the host-setting's medical model (Dane \& Simon, 1991). Because they saw a need that they knew must be addressed, social work foremothers navigated the difficult boundaries of social work and medicine as they helped to found medical social work in the early 1900's. Although many know about Ida M. Cannon's becoming chief of social work at Massachusetts General Hospital (MGH), few have access to the words, lived history, and wisdom of other foremothers of health social work practice. As Social Work Department Chairs in the most important teaching hospitals of their times and officers in the American Association of Hospital Social Workers (which later became the American Association of Medical Social Workrs and then merged with other specialty organizations to become the National Association of Social Workers), thes deeply committed women were the leaders of their time and thus the proven experts in the field. Here, we draw on interviews with many of those foremothers from a project of the first author; these interviews have not been previously published.

In post-hoc analyses of roles and responsibilities initially undertaken by the second author, themes were derived from the original interviews. We believe these themes have value on their own as an historical account of how these women pioneers navigated the early challenges of developing the social work role within health care. As a result of contemporary 
casebooks the first author collected and edited, the most recent done by both authors, we also use an extensive discussion section to analyze how the themes from the early interviews continue to have relevance for social workers today. Because the themes all relate to social workers' response to needs created bu the contextual demands of economic and policy changes, public health crises, wars, technological advances and new and underserved populations, they are as relevant to today's practitioners as they were to the foremothers.

We elect to limit discussion of methods in order to provide more material that illustrates the wisdom of the early practitioners. We organize the findings according to the themes derived from the codes of roles and responsibilities identified in the interview data that cohered around the reasons for the work social workers did historically. These will be elaborated below. In summary, they are in response to the needs: (a) created by wars; (b) of new and underserved populations; (c) created by public health crises; (d) created by technological advances; (e) of organizations; (f) resulting from economic and policy issues; and (g) of clients. The latter 'response to client needs' was, of course, universal within the data.

\section{Methods and Data}

This is a post hoc analysis of interviews conducted and transcribed by the first author in 1976 as she traced the history of the beginnings of medical social work. Although these interviews were bound and housed at three academic libraries, access to the words of these foremothers has been quite limited. The second author elected to code the interviews using qualitative techniques of open coding followed by axial coding to derive themes within the interviews that related to the two sensitizing concepts of roles and responsibilities (Beeman, Kelle, 2007). These two sensitizing concepts were selected as the two authors had recently collaborated on a new casebook collecting case studies from current social workers in health care 
and a study was underway to consider what best practices might be identified in health social work (Author and Author, in press). After both authors independently coded the roles and responsibilities, a common coding scheme was agreed upon, with little need for revisions.

The original data include interviews completed by 22 informants in 1976 (Author 1, 1979). It should be noted that all gave their permission to have their true names included as part of the interviews and they will be used here to enhance the historical understanding. Here, we analyze data from the interviews and derive themes related to how these founders viewed the roles, responsibilities and goals of health related social work. Information about the informants' education and professional experience is available (Author 1, 1981). The themes from the original interviews are reported in the Results section. In the extended Discussion section, the themes that emerged from the original informant data are then compared with themes emerging from four edited casebooks that, in total, include 80 unique case reports of social work practice in health settings between the years 1980 and 2010 [Author 1, 1982, 1989, 1997; Author \& Author, 2010). Each case reflects the strengths of case studies, namely depth, richness, completeness and within-case variance (Flyvbjerg, 2011).

Initial coding of roles, responsibilities, and goals was done using only the original interviews as data by both authors. Using constant comparison, we later analyzed the casebook data to see if these early roles, responsibilities, and goals continue in contemporary social work practice. Best practices that emerged from contemporary casebook data analysis have been reported elsewhere [Author \& Author, in press]. Both author/reviewers came to the same coding of themes independently. A table demonstrating the presence of the original themes in each of the cases is available.

Resultant Themes 
It must be noted that the overarching theme was clear and strong- early social workers in health care responded to the needs of the medical establishment, patients and others affected by public health issues. The value of service (expressed in the NASW Code of Ethics as helping people in need, addressing social problems, and elevating service above self-inteest) was deeply rooted within all roles and responsibilities they elected to fulfill (NASW, 2008). In many ways, these women were fearless - volunteering to go to the front in wartime, going into neighborhoods where no middle class woman was to venture, working with those who had what were considered to be "unspeakable diseases" at the time. They went with neither gun nor medical kit. It was not that they knew exactly how to intervene to solve every problem. They were drawn by the value of service; they became involved because they were needed, and then they brought to bear what interventional capacities they had or could acquire. Each theme identified here shows an area where social workers deemed it within their purview (role) to provide social work services in response to the identified needs.

In Response to Needs Created by Wars

Many of the original informants worked with the Red Cross beginning in World War I. Mary Kay Taylor went to Europe with the Red Cross. She said:

No one had heard of social workers, nor knew what they were supposed to do. I wrote to all families of the men who had died in hospitals and helped coordinate work as others from the Red Cross came and went, and I kept track of the files and found the companies of men who were admitted to the hospital so they could provide information about men who were missing. I went to funerals every day and came to dread the sound of TAPS. Taylor attended many funerals and wrote letters to the families of deceased troops. She reported a very funny story of bringing up the end of a soldier's funeral procession; a village cow joined 
her, which she found frightening, yet she adapted and managed to even "collaborate" with the cow by the end of the funeral. Josephine Barbour also described work overseas:

I went with the hospital unit actually in North Africa and I was in charge of the Hospital Unit there, and I went up to Algiers headquarters to head the hospital services for the Mediterranean theater. That was an experience! What we did with patients during a war situation in an army hospital was quite different. I think that one of the other things that developed during the war was the way in which we worked with patients. Dr Edward Bland was one of the medical men who developed the ward conference which the visiting men, the residents and interns, the nurses and social workers could help with and so this developed the ward conference [case conferencing] out of a war situation actually. That was here at MGH. It was a way of expediting things.

Barbour reported that single referrals had been the rule prior to the war, but as a result of the war, interdisciplinary case conferences became more customary. Interdisciplinary teams were formed, and there was not a division between medical and psychiatric social workers; the social worker managed both roles. She also discussed tensions involved with being part of the team.

This was a new experience in social work because in a sense what you were helping to do was to rehabilitate the patient to return to the battlefield. . This was your goal, to get the soldier back into the line because we needed the troops. The girls were bothered by this because you were getting them ready to be sent back in to be killed. This was very hard to cope with. You would talk with them and the boy said "Yeah, you can push your luck too far. I've made three invasions and made it. I'll never make the fourth." Social workers were developing new interventions "on their feet" and in collaboration with the full health care team. 
As Barbour and others returned home, their wartime experiences deeply influenced the development of hospital social work

In Response to the Needs of New and Underserved Populations

Much as social workers responded to the needs of veterans and their families, they also responded to other new and often marginalized populations. Even in the early 1900's, social work values and responses were guided by ethics relating to helping people in need, mobilizing against social injustices and respecting all people. Harriett Bartlett provided an early example of meeting such needs in her work with Irish immigrants:

We were the first and only ones to go out from the hospital often and were again the link for the hospital to work with the community. You might be quite horrified by some of the homes, particularly the Irish homes, many of the poorer homes where everything seemed to be in terrible disorder when you went in. The clothes and food were all around, and sometimes really quite dirty, and you couldn't help being rather shocked by that and wondering if it was a good place for the children. But before we really got very far on that, we came to realize that the really remarkable warmth and love of the mother in this instance gave the children the security of affection at home. I mean we learned from the immigrants.

Here we see the initial sense of "othering" followed by a growing respect for the dignity and worth of all and the ability to see strengths where one may have expected to see needs. Working with marginalized populations early in social work history seems to have provided the sensitization that all people have strengths, even the Irish who were terribly ostracized at the time. 
Theodate Soule started with the Children's Bureau but quickly became involved with public health aspects of the work. She talked about her participation in the studies carried out by the federal Children's Bureau in the 1930's.

One study was of what happened to children in six different states in relation to the crippled children's program, and my study was in relation to the discharge of children and their after-care plans. We each had three workers, and each worker had two states. . . My states were New Jersey, Virginia, Alabama, Kentucky, Michigan, and Minnesota. But that was very revealing to me. It was dreadfully disturbing that you could get care if you had been born in one part of the country but not another. On the eastern seaboard, at least it was possible, but some of the other states were just dreadful. These children had gotten some kind of care but in many instances it hadn't done them much good because there wasn't any follow up that made it possible for them to live a decent life still handicapped.

The studies of the Children's Bureau made it possible for care to be more equitably distributed. These early social workers made it their business to identify and challenge social injustices. Similarly, Mazie Rappaport started programs for the little served prostitutes of Baltimore. The prostitutes' experience was just tremendous. See, when I first began working with prostitutes, I thought that was going to be a medical social work job. These were all really effective girls and women. We cured their venereal disease and they'd just up and became infected again. Well, on the West Coast, they were having all the prostitutes take long-term intensive psychiatric help to see why it is they went into prostitution. I could say in two sentences - [women] had to go into prostitution to support her children, or mother, or maiden aunt, or couldn't take the rap by getting a decent job. 
Social workers were getting a first-hand understanding of the structural roots of poverty and attempts to survive under duress. They were providing direct services, while at the same time recognizing the inequities of the economic system and the way services were distributed and delivered. It is notable that the social workers in Baltimore did not get distracted by the growing love of psychoanalytic work, but stayed pragmatic in their approach.

\section{In Response to Needs Created by Public Health Crises}

The interview data showed much evidence of attention to early public health crises, especially for the early social workers of the 1910's to 30's as they dealt with the issues of polio, tuberculosis and syphilis. Josephine Barbour discussed the mother's club she helped develop for mothers of children with polio; the prescribed treatment for the children was six months of bed rest. She noted "The mothers met together and talked over their problems of keeping children in bed, which were many." Ultimately, they developed a craft program for the children and worked with the families to manage the anxieties they had about their children developing handicaps. They developed both the children's activities program and the parent support group in direct response to the needs of this new public health population.

Bartlett describes the early treatment of tuberculosis and the way she and the brand new social work department at MGH managed:

Very early, there were three of us young workers in the outpatient department and one of the problems was with this concern with tuberculosis, which of course was then a dread disease and the death rate was high, and it was feared. And we three workers were waiting on the floor below to talk with the patients who were sent down from this TB clinic. There were quite a number of them who were told for the first time that they had tuberculosis. Well, it was a tremendous opportunity and experience. These people would 
come down, most often young people, and sit down with you. They were of course terribly upset and shocked and they might break down and weep and we didn't know it then; we didn't have any psychiatric background, but we had learned that it helped to listen, and we would sit and listen until they were ready to talk. And then we were able to tell them positive news because, by then, the State had sanatoria and they were available for care if they needed it.

Social workers were often at the forefront of humanizing treatment for new diagnoses. They work to identify need and then link individuals to resources. They had to learn on their feet that "it helped to listen" and to use their problem solving skills to begin creating and linking to resources.

\section{In Response to the Needs Created by Technological Advances}

Technological interventions, including new medications and surgical and other techniques, depend on new knowledge. Each advance requires adjustment on the part of individuals, medical systems and societies (Ogburn, 1922/1957). For example, the restricted bed rest for polio mentioned above was a form of technology. In another example, Ruth Cowin talked about how the then-new treatment for syphilis required innovative social work interventions:

One of the problems with syphilis was to keep the person coming for 18 months to us for treatment once a week, so what we did, I had a routine interview with every single one of these people and this is where I first got my interest in public health. As far as the newly diagnosed patients with syphilis, we tried to get out their grief or anger at the same time we tried to impress upon them how serious it was to continue with this treatment. 
New technological interventions could not work if they were not implemented and social workers played a key role in helping patients be informed about their care, and enhance adherence to treatment.

Advances in assessment, the creation and use of prostheses, and rehabilitation for people with mobility impairments were important also. Mary Poole opined:

The thing that was the most pressing was a notion that the physically handicapped person (in terms of the young adolescent) was only worth being trained for a trade like watch repair. . Something about his brain wasn't as good as the unhandicapped, and he was not considered proper for college bound high school education but trade school education. I remember one young boy who had had polio and he was going to the School for Crippled Children and when he reached the $8^{\text {th }}$ grade they offered him shoe repair or watch repair and he refused to take it. At that point he lost all help for orthopedic appliances and that sort of thing because he was not following into the pattern which was expected... I think it was World War II that taught us a lesson that one could lose a limb or one could be maimed in various ways and still have a brain.

In a post-polio era, social workers were part of exhibiting this change in thinking; it became important to recognize the potential of people to use their brain even if their bodies were impaired.

In Response to the Needs of Organizations

Early social workers also balanced the sometimes differing demands of both clients and organizations. Rappaport reported:

That was the year of the last large polio epidemic. There were all these pressure systems about how social work should begin. I started with the premature babies and then 
continued with the elderly because of the needs of the chronically ill. . I was there for a year by myself and couldn't take on more than emergencies. I had to get the welfare department to do something about those babies who were boarding in the hospital and provide care in homes. Also, homes had to be made safe for babies to be discharged. What I had to decide was that if you used the organizations that were in the community, they would do the things that had to be done.

Finding fresh ways of interfacing with the community grew from the needs of clients and from social work's realization that their organizations could not meet all of their patients' needs. Likewise, the hospitals had to respond to social workers' identification of new organizational needs. Josephine Barbour described the new role of emergency room social worker: Another was the development of the emergency ward service (EW). We used to be called when they wanted to refer a patient. The orthopedic doctor would call the orthopedic worker down and the surgical workers would go down to the EW at the request of the surgeons. We were concerned about what was happening to families who came to the EW, as well as the patients. We developed and had quite a large group of workers working just in the EW and overnight ward. Some loved it and others hated it. Ultimately, a designated person became the full time EW social worker and a new social work role was developed. Elizabeth Wheeler discussed an additional organizational innovation: Another thing that social service was in on the ground floor at the policy level was community clinics. Two were in Chelsea and Charlestown, and their staff were doctors and a social worker and patients could go there and not have to come to town. This is the coming thing for hospitals to have satellite clinics. It has worked out quite well. 
As hospitals sent satellites into the community, and social workers looked in the community for organizations that might assist patients, the social work role rapidly became one of assessing how community services could be leveraged to create new opportunities to serve patients in the community.

In Response to the Needs Created by Economic and Policy Issues

Irene Grant Dalrymple reported World War I as "a pretty bad experience for a young girl during the hot summer of 1918, coming from a country college and a country home." Yet her work demonstrates an early social work response to economic need.

We were very concerned with the welfare of the families of the men who had gone to war. They were supposed to allot part of their money for their dependents, wives, brothers, sisters, and the government added, I guess, an equal amount, but this was new for the national government and the program took a long time to get that money, and the Red Cross helped many families who were waiting. My supervisor every week went over all my cases with me. The purpose was not to improve me as a social worker but to see that the family was getting everything it needed.

The government was taking seriously its role as the safety net provider at that time, and social work took seriously its role as the locator and distributer of resources.

Many of the interviewees were profoundly affected by their work during the Great Depression. Bartlett reported:

Our beginning as I remember it was with the FERA which was the medical relief that came in 1934. Well, we began right off thinking about it and set up a committee with a rather odd name - Medical Care in Community Health - meaning that it was the broader 
aspect, not casework. One of the first things that committee did was to arrange to study how this medical care under FERA was being given to relief clients.

Bartlett's concern was to assure provision of services. Rappaport also discussed the role of social work and she provided a cautionary view:

The other thing I remember about the Depression was that there was tremendous effort made to try to find out whether people were or were not employable because the WC would set up all these public works projects-CCC, all of these so that they always needed to know what the physical health of the individual was. We always started with that...And what we worked for was to have one spot where people were examined so that there would be some base for determination...to have one doctor make a judgment or to have some standard set up because otherwise many clients were able to persuade their doctors that they could or couldn't work.

It seems social workers were co-opted, "buying" the medical model idea that everyone needs to have a physical exam, "buying" the resource-restraint/ governmental idea that people must be categorized into employable or not. That said, Ms. Rappaport was also one of the first to really discuss the way inappropriate referrals would come from physicians and her ultimate response:

Don't tell us [we said to the doctors] if a patient needs a homemaker. Tell us what the patient's limitations are and we will work with the family to see if some of this can be provided for the family or whether other plans can be made.

\section{In Response to Clients' Unmet Needs}

Often, the clients' unmet needs drive social workers to locate or create interventions and/or services. In this vein, Ruth Cowin decried the forces within and outside of social work that wanted to isolate concrete services and attend only to emotional and psychological concerns: 
What happened when this change came in practice was that we got ourselves out of doing any kind of tangible things. It suddenly became a dirty word, and I think we failed to take it into our assessment in terms of social functioning. I have no idea why, but I know that students who come from good schools of social work - when I was running a department at Cambridge, I really and truly had to reorient them. One of the things that my staff tells me that they're most appreciative of was being made to do enough of a screening to have some notion of all the areas of social functioning that are important. If there are children in the family, what is the parents' functionality? How well are they parenting? Are the parents working or unemployed? Do they have any marketable skills? What is their fiscal functioning? How many young social workers have I asked, "Where are these people getting their income?" This is very important to know. For some reason or another, we throw the baby out with the bath water. We're getting back to it. For a while, we were abandoning the population that we had worked to serve. Cowin notes that the purpose for these types of questions is not to exclude people from services, but to assure that they are being served, connected to needed resources, and their well-being is being enhanced. Several of the interviewees were associated with MGH and other Boston hospitals at the time of the Coconut Grove nightclub fire in 1943. They discuss the ways they were called in to work the night of the fire to console grieving family members and assist in the identification of bodies. Barbour notes:

The whole staff was mobilized to work just with the families and some of the patients, so there was a great lot of grief reaction which came out of the many losses that families had. We worked day and night at the hospital the first few days. Actually, the workers 
helped to identify some of the bodies and went with the families. So this was another role which we hadn't been entirely used to- the social worker in the disaster.

We see the incredibly adaptive role of the social worker as the needs of individuals, families, medical settings, and community are all met at a time of crisis.

\section{Discussion}

Material drawn from interviews with 22 early medical social workers shows themes for social work that continue to be present today and also continue to affirm the call of social work as exemplified in the NASW Code of Ethics (2008). Here, we relate the themes that emerged from those first social workers to current social work practice in health care. A critical perspective on this analysis may lead us to ask why the social work role is always one of response, a role that means social workers experience the force of external demands. Yet, professional responses to the needs that evolve due to war and disasters, to economic changes, and to technology development or public health threats, by nature must occur after the event has occurred, as most cannot be predicted or avoided. A part of who we are as social workers is our responsiveness. This continues from the founding of health social workers in the early 1900's through today, as we will illustrate by tying the themes identified above into current social work practice as described in the four casebooks edited by author 1 (the last, in collaboration with the second author).

It should be noted here that to cite each case/chapter separately in the reference section is unwieldy; therefore, we use an abbreviated citation in text. The author of the chapter/case is identified, but the casebook within which the case was published is abbreviated. For example, a case from the first casebook (1982) is indicated in the manuscript as (Schmid in Author 1, 1). In Response to Needs Created by War 
Above, Josephine Barbour describes how early interdisciplinary team meetings evolved during wartime. The interdisciplinary team meetings developed for wartime use but have been broadly adopted since and case conferencing and interdisciplinary teamwork is seen as crucial to holistic, effective health service (Mizrahi \& Abramson, 2000). Stress debriefings also evolved from wartime practices and continue to be used today (Martin, in Author 1, 3).

War service pushes social workers into new service delivery interventions and structures. Presently, there are 9,000 social workers employed by the Department of Veterans Affairs, 500 in the active military and thousands of civilians working for the Department of Defense (NASW Center for Workforce Studies \& Social Work Practice, 10/1/09). Findley (Authors 1/2, 4) writes of work with a veteran returned from Operation Iraqi Freedom (OIF) with a minimal traumatic brain injury (mTBI) and within a newly developed structure of care, the War Related Illness and Injury Study Centers (WRIIC). She works with the client and family and finds herself educating referral sources about minimal traumatic brain injury.

Clearly, new structures (WRIISC), diagnoses (mTBI), and policies mean the development of social work skills and strategies that help members of the military and their families with adjustment and reintegration. The reality is that many vets are returning with unseen traumatic brain injury and other physical and psychological wounds. Thus, every social worker is likely to work with vets in substance abuse programs, community shelters, mental health agencies and among the general public (Savitsky, Illingworth, \& DuLaney, 2009). The inherent complexity of working with veterans requires interdisciplinary involvement and the skills and structures social workers developed during WWI continue to this day.

In Response to the Needs of New and Underserved Populations 
Heeding the NASW Code of Ethics (2008), social workers advocate for needed services, then and now. Whether recognizing the needs of children with disability or the needs of prostitutes in the mid-1900's, or recognizing the needs of individuals with severe mental illness who are homeless (Barker in Authors 1/2,4) in 2009, the same critical features are present in contemporary social work. Social workers ideally recognize needs and view strengths through a lens of functionality rather than parochial morality. Underserved populations often come to social work's attention because they have been overlooked by society and are marginalized and viewed often dismissively. Social workers work to serve those who have been overlooked by society and use policy practice to influence society to not only recognize such groups, but to reckon with the societal structures and policies that create the social problems affecting them. Hidden populations such as those with Intimate Partner Violence (Stewart in Author 1/2, 4), individuals who are viewed with moral condemnation such as adolescent parents (Schmid in Author 1, 1; Rounds in Authors 1/2, 4), and individuals who are wronged by business and political practices such as those exposed to uranium (Dawson in Author 1,3, \& Authors 1/2, 4), are among the many served by social workers in the current environment.

\section{In Response to Needs Created by Public Health Crises}

Reading Bartlett's words about the tuberculosis clinic is reminiscent of the beginnings of the HIV/AIDS epidemic (Getzel in Author 1 1,2), and populations newly affected by HIV/AIDS (Walther, in Author 1, 3; Blackwood, in Authors 1/2, 4; Norris in Authors 1/2, 4). Populations continue to emerge with varied levels of stigma and lack of societal attention as we can see in the current obesity epidemic and its subsequent Type II diabetes (T2DM) in minority children (Ciporin, in Authors $1 / 2,4$, p. 86. 
Newly recognized public health needs require creative interventions. Whether entertaining children on bed rest, making learning about healthy eating fun, or developing outreach programs to youth around HIV testing (Robinson

, in Authors 1/2,4), actions derive from social workers' commitment to hearing individual's needs, recognizing group level needs, and developing responsive programs.

\section{In Response to the Needs Created by Technological Advances}

Whether syphilis medication regimens or the dawning of rehabilitative equipment enabling functioning of those with physical disabilities, early social workers bridged the interface between the development of new technologies and people's responses to those new technologies. Many advances in technology demand new perspectives, ethical understandings and help with emotional ramifications. Now, technological advances span everything from micro level understandings of genetic anomalies (Author 2 in Authors 1/2, 4; Scarvalone, in Authors $1 / 2,4$ ) and fetal surgery (Hudson in Authors $1 / 2,4$ ) to environmental factors related to radiation exposure (Dawson in Author 1,,3;, Authors 1/2,4) and health conditions such as asthma (Boyd in Authors 1/2,4) and cancer (Moulton in Authors 1/2, 4; Naik in Authors 1/2, 4). New medical technologies require patients to adapt to new regimens and new ways of being in the world. Social workers are inspired to learn new and creative ways of engaging affected individuals to help them and their families adapt, while also working to understand contextual dimensions that require advocacy and program development.

\section{In Response to the Needs of Organizations}

As the early social workers finally quit being called from their specialty areas in the hospital down to the emergency ward, the social work role for the emergency room (ER) was born. Social work in ER's and trauma units are now viewed as vital in health social work today 
(Auerbach \& Mason, 2010; Fujimoto in Author 1, 1; Johnson in Author 1, 1). Likewise, early social workers started community outreach as a way of meeting patients' needs that the hospital could not meet. Now, community outreach is commonly used as social workers try to meet the needs of their clientele. Organizational collaborations are another innovation championed by social workers. Claxton et al. (in Authors $1 / 2,4$ ) report the experience of an interdepartmental collaborative to provide community-based services to at-risk mothers and newborns; they worked to integrate services between the Division of Maternal, Child and Family Health of a city's Health Department, and Department of Human Services. These organizations work together to implement the federal Child Abuse Protection and Treatment Act that has medical workers notify child protective services of infants identified at birth as affected by prenatal drug exposure. Their collaboration assures follow-up in the community for purposes of supporting the mother-baby dyad, rather than for punitive reasons. Organizational pressures and responses have often been recognized as needed by social workers who are at the intersection of these multiple systems where they can identify and advocate for the needed changes. Social workers are frequently at the forefront of building these types of collaborations in response to observed needs within and among organizations charged with serving the public. Social work training that encourages macro policy and programming understandings make this type of collaboration building possible and fit well within the social work ethic to promote social justice. In Response to the Needs Created by Economic and Policy Issues

Evolving economic and policy environments nearly always imply some degree of resource allocation. The early social workers were at the forefront of assuring that veteran's families and the poor were able to get the economic support allotted to them. Yet they also occasionally were co-opted into the medical model. Social workers continue to negotiate social 
work roles in "host settings" be they medical or community agencies (Lesser, 2000). When economic times are tight and policies work to exclude rather than include people, social workers remain sensitized to what constitutes appropriate social work practice (Keigher, 2000). Current social workers run into challenges in for-profit renal dialysis units when they try to advocate for clients and find their own jobs in jeopardy (Blades in Authors 1/2, 4), when social workers need to challenge the medical powers-that-be to advocate for individuals' self-determination in regards to transplantation (Miller in Authors 1/2,4), and when social workers are called to create "high touch, low-tech" relationships in a "high tech, low touch environment" (Maus in Authors 1/2, 2010; Zelinka in Author 1, 1). As social workers work within the confines of medical host settings, within economic and policy restraints, in the best social work practice, social workers understand structures and systems and remain cautious about over-medicalizing situations or moving into roles of social control. Once again, social work training in understanding how social structures and policies impact individuals is crucial in being able to respond to promote socially just resource allocation.

\section{In Response to Client's Unmet Needs}

Early social workers responded to the needs of individuals whether they were the concrete needs of mental health clients or the needs of individuals after a community disaster as during the aftermath of the Cocoanut Grove nightclub fire. These historic roles continue to this day as social workers work in health settings where crisis is the rule rather than the exception. Social workers serve neonatal intensive care units (Taksa in Author 1, 2; Stewart in Authors 1/2, 4), hospices (Brooks in Authors1/2, 4; Zisserman in Author 1, 3), in combat settings (Martin in Author 1, 3) and burn centers (Blades in Author 1, 3; Hahn in Authors 1/2,4) as well as in many situations of personal crisis for individuals and families. In each of these settings, social workers 
rise to the NASW Code of Ethics call "to enhance human wellbeing and help meet the basic human needs of all people, with particular attention to the needs and empowerment of people who are vulnerable, oppressed, and living in poverty" (NASW, 2008). The role continues to include sensitivity to the unstated needs of individuals and an ability to conduct a holistic assessment of the needs of each individual, family and community.

\section{Conclusions}

Social work roles in health care evolved from early social workers experiences of being pulled into new areas to attend to and manage previously unmet needs. Whether going off to battle fronts to assist with soldiers' reactions or working to support soldiers' families at home, these early social workers were ready to adapt their skills to the needs of new settings, previously unrecognized communities, and individuals and families with whom they worked.

In 1948, Dora Goldstine, the President of the American Association of Medical Social Workers noted:

I have read the reports of the preceding fifteen presidents. Almost uniformly, they explained that the year in which they had been writing had not been a normal one - war, post-war, depression, the New Deal, another war, and, then, post-war periods all followed in quick succession, and brought their special problems to medical social work. No organization is simply the result of planning. . . Often fortuitous circumstances shape programs and model structure, and wisdom is shown in the way these pressures are met. The fact that this Association reflected, not a means of benefit to its members, but development to its members and of a profession, I feel sure, has been the keystone of its stability and success (Goldstine, 1948, p. 46). 
An important aspect of professional response is that while social workers may respond to the external event/ situation, we do that in a way that maintains the claim to our skills of assessment, problem-solving, and intervention while being animated by the unique value set encoded in our Code of Ethics (2008). Like the foremothers of the profession, we assess where our professional judgment requires that we adapt, and, when necessary, we advocate for social justice and/ or policy or program changes. On a practical level, like Rappaport, social workers do not automatically accept the physician's interpretation of the problem and its solution, but instead stop to understand the clients' experience of problems and develop a full understanding of their desired solutions and available resources. Social workers interrogate the impetus for economic initiatives and policy approaches to assure that they are implemented to support the well-being of all individuals rather than re-inscribing power over those who are already marginalized. We advocate within our hospitals, agencies, and other settings to assure that in meeting needs on all levels, we are not continuing a status quo that includes avoidable injustices. Our professional call to provide service need not define us as handmaidens to those entities which issue the call, but merely require that we arrive ready to assess the needs for ourselves and thereby ascertain who to help, assuring that those most likely to be oppressed or marginalized will be the first priority (NASW, 2008).

In examining the history through the words of these early social workers, we offer a way to regard the greater profession of social work. Several early social workers said they bent the rules or were allowed to bend the rules because someone was on the edge of too old or stayed with the service longer than usual; others expanded the definition of the client to include others (family members, a teacher, an employer, a mother of a teenThe ways in which these early social workers in health care honored social justice and responded to need (Salas, Sen \& Segal, 2010) 
can serve as examples of how common values and skills provide an overarching identity to our profession no matter what our particular specialization. The historical perspective reminds the profession that social work values have animated practice from its inception and continue to be a binding aspect of our work (Swenson, 1998).

\section{References}

Auerbach, C. \& Mason, S.E. (2010). The value of the presence of social work in emergency departments. Social Work in Health Care, 49(4), 314-326.

Beeman, S. (1995). Maximizing credibility and accountability in qualitative data collection and data analysis: a social work research case example. Journal of Sociology and Social Welfare, 22(4), 99-114.

Dane, B.O. \& Simon, B. L. (1991).Resident guests: Social workers in host settings. Social Work 36(3), 208-213.

Flyvbjerg, B. (2011). Case study. In N. K. Denzin \& Y. S. Lincoln, Y.S., The Sage handbook of qualitative research, (pp. 301-316). Los Angeles: Sage.

Gibelman, M. (1999). The search for identity: Defining social work - Past, present, future. Social Work, 44(4), 298-310.

Goldstine, D. (1948). Evaluation of a professional organization. Bulletin of the American Association of Medical Social Workers 21(July), 46-49.

Kelle, U. (2007). The development of categories: Different approaches in Grounded Theory. In A. Bryant and K. Charmaz, The Sage handbook of Grounded Theory (pps. 191-213). Los Angeles, CA: Sage.

Keigher, S. M. (2000). The challenge of caring in a capitalist world. Health and Social Work, 25(2), 83-86. 
Author 1, T.S. (1979). Eleven medical social interviews: A contribution to the oral history of social work in health care. Archived at the University of Minnesota Social Welfare History Archives, University of Pennsylvania Libraries and the Simmons College Library.

Author 1, T.S. (1981). Medical social work: The pre-professional paradox. New York: Irvington.

Author 1, T.S. and Associates. (1982). Social work in health settings: Practice in context. New York: Longman.

Author 1, T.S. and Associates. (1989). Social work in health settings: Practice in context. New York: The Haworth Press.

Author 1, T.S. and Associates. (1997). Social work in health settings: Practice in context $\left(2^{\text {nd }}\right.$ edition). New York: The Haworth Press.

Author 1, T.S., Author 2, J.L.M. and Associates. (2010) Social work in health settings: Practice in context ( $3^{\text {nd }}$ edition). New York: The Haworth Press.

Lesser, J. G. (2000). Clinical social work and family medicine: A partnership in community service. Health and Social work, 25(2), 119-126.

Mizrahi, T. \& Abramson, J. S. (2000). Sources of strain between physicians and social workers: Implications for social workers in health settings. Social Work in Health Care, 10, 33-51.

National Association of Social Work. (2008). Code of Ethics. Retrieved January 15, 2012 at http://www.socialworkers.org/pubs/code/default.asp .

NASW Center for Workforce Studies \& Social Work Practice. 10/1/09. Workforce.socialworkers.org/studies/.../Government\%20agencies.pdf 
Ogburn,W.F. (1922/ 1957).Cultural lag as theory. In O. D. Duncan (Ed) On culture and social change (pp.86-95). Chicago: The University of Chicago Press.

Salas, L. M., Sen, S, \& Segal, E. A. (2010). Critical theory: Pathway from dichotomous to integrated social work practice. Families in Society: The Journal of Contemporary Social Services, 91(1), 91-96. DOI: 10.1606/1044-3894.3961

Savitsky, L., Illingworth, M., \& DuLaney, M. (2009). Civilian social work: Serving the military and veteran populations. Social Work, 54(4), 327-339.

Swenson, C.R. (1998). Clinical social work's contribution to a social justice perspective. Social Work, 43, 527-535. 